\title{
Monoclonal Gammopathy Responsive to Decitabine Given for Acute Myeloid Leukemia in a Frail Patient
}

\author{
Pasquale Niscola Benedetta Neri Luciana Morino Paolo de Fabritiis
}

Hematology Unit, Sant' Eugenio Hospital, Rome, Italy

The concomitant occurrence of acute myeloid leukemia (AML) and plasma cell dyscrasias has been sporadically reported [1-4]. This association may represent an incidental finding rather than a disorder of a common pluripotent stem cell. Although the pathogenesis of these coexisting disorders is unclear, a pathogenetic involvement of the inflammatory cytokine, interleukin (IL)-6, and the tumor suppressor p53 (TP53) has been suggested [5]. In addition, aberrant DNA methylation, which causes the inactivation of the promoter and consequently the inhibition of tumor-suppressive gene transcription (gene silencing), is a well-known and common event in AML [6] as well as in malignant plasma cell disorders [7-9], including monoclonal gammopathy of undetermined significance (MGUS) [7]. In particular, methylation changes in some upregulated genes were found in up to $17 \%$ of samples from MGUS patients [7]. Significant increasing apoptosis of malignant plasma cells exposed in vitro to epigenetic agents, such as azacitidine [9-10] and decitabine [11], has been demonstrated. In addition, simultaneous clinical responses to azacitidine in cases of MGUS concomitant with chronic myelomonocytic leukemia [12] as well as of AML coexisting with multiple myeloma [5] have recently been reported. However, although it is not unexpected, the clinical antimyeloma effect of decitabine in patients with coexisting AML and plasma cell disorder has not be observed in clinical practice so far. Herein, we report the case of an older AML patient with MGUS, diagnosed at the initial diagnostic work-up after admission due to symptomatic pancytopenia.

The patient was a 74-year-old man who presented with an oligoblastic myelodysplastic syndrome-related AML. At disease onset (November 2016), his bone marrow evaluation showed 23\% myoblasts and 10\% infiltrating malignant plasma cells associated with a serum IgG-kappa paraprotein (about $15 \mathrm{~g} / \mathrm{L}$ ), although the occurrence of overt multiple myeloma or amyloidosis was ruled out by the appropriate examinations. Therefore, the simultaneous occurrence of AML and MGUS was diagnosed. Given the patient's age and the burden of comorbidities, he was unsuitable for standard AML remission induction chemotherapy. Thus, according to regulatory prescription and institutional practice, he was started on decitabine $\left(20 \mathrm{mg} / \mathrm{m}^{2}\right.$ for 5 days every 4 weeks) given with life-prolonging and palliative intent. Hypomethylating therapy with decitabine allowed for the achievement of complete AML remission that was firstly demonstrated and subsequently confirmed after 4 and 12 treatment courses, respectively. Meanwhile, a progressive disappearance of the monoclonal peak from the electrophoretic pattern was observed, although the paraprotein was still only minimally detectable on immunoelectrophoresis until 12 months after the initiation of decitabine therapy. In addition, plasma cells were not found on bone marrow smears or the trephine biopsy specimen. This pattern of response has so far been stably maintained by regular epigenetic therapy (10 cycles of decitabine), which the patient continues to receive without remarkable side effects. Therefore, the 2 disorders, AML and MGUS, which were both concomitantly progressive before treatment, were responsive to decitabine. The complete remission of AML and, at the same time, the disappearance of paraproteins from the electrophoresis was achieved. While some evidence of epigenetic mechanisms exerted in vitro in malignant plasma cells by decitabine have been reported [11], no evidence regarding the clinical activity of this agent in the setting of plasma cell dyscrasia has been published to date.

In conclusion, we have provided an incidental observation of anecdotal value that is in line with our previous report on

\section{KARGER}

(c) 2018 S. Karger AG, Basel
Pasquale Niscola, MD

Hematology Division, Sant' Eugenio Hospital

Piazzale dell'Umanesimo 10

IT-00144 Rome (Italy)

E-Mail pniscola@gmail.com 
chronic myelomonocytic leukemia patients [12], in which we observed the disappearance of MGUS under epigenetic therapy with azacitidine. Therefore, both azacitidine and decitabine, which are hypomethylating agents available in clinical practice, demonstrate novel and highly rel-

\section{References}

1 Shoenfeld Y, Berliner S, Ayalone A, Shaklai M, Djaldetti M, Pick AI, Pinkhas J: Monoclonal gammopathy in patients with chronic and acute myeloid leukemia. Cancer 1984;54: 280-283.

2 Levinson SS, Elin RJ, Yam L: Light chain proteinuria and lysozymuria in a patient with acute monocytic leukemia. Clin Chem 2002; 48:1131-1132.

3 Van Camp B, Reynaerts P, Naets JP, Radl J: Transient $\operatorname{IgA}-\lambda$ paraproteinemia during treatment of acute myelomonoblastic leukemia. Blood 1980;55:21-25.

4 Niscola P, Catalano G, Fratoni S, Scaramucci L, de Fabritiis P, Caravita T: Concomitant transformation of monoclonal gammopathy of undetermined significance to multiple myeloma and of essential thrombocythemia to acute biphenotypic leukemia 37 years after initial diagnosis. Blood Res 2013;48:228-230. evant antimyeloma effects. Our findings suggest the need for further evaluation of the potential role of epigenetic therapy, either alone or ideally in combination with other antimyeloma compounds, in the treatment of patients with plasma cell neoplasms.

5 Oka S, Ono K, Nohgawa M: Successful treatment with azacitidine for the simultaneous occurrence of multiple myeloma and acute myeloid leukemia with concomitant $\operatorname{del}(5 \mathrm{q})$ and the JAK2 V617F mutation. Ann Hematol 2017;96:1411-1413.

6 Spencer DH, Russler-Germain DA, Ketkar S, Helton NM, Lamprecht TL, Fulton RS, Fronick CC, O'Laughlin M, Heath SE, Shinawi $\mathrm{M}$, Westervelt $\mathrm{P}$, Payton JE, Wartman LD, Welch JS, Wilson RK, Walter MJ, Link DC, DiPersio JF, Ley TJ: CpG island hypermethylation mediated by DNMT3A is a consequence of AML progression. Cell 2017;168: 801-816.e13.

7 Galm O, Wilop S, Reichelt J, Jost E, Gehbauer G, Herman JG, Osieka R: DNA methylation changes in multiple myeloma. Leukemia 2004;18:1687-1692.

8 Piras G, Monne M, Palmas AD, Calvisi A, Asproni R, Vacca F, Pilo L, Gabbas A, Latte G: Methylation analysis of the phosphates and tensin homologue on chromosome 10 gene $(P T E N)$ in multiple myeloma. Clin Epigenetics 2014;6:16.

\section{Disclosure Statement}

The authors have no conflicts of interest to disclose.

9 Khong T, Sharkey J, Spencer A: The effect of azacitidine on interleukin- 6 signaling and nuclear factor $-\kappa \mathrm{B}$ activation and its in vitro and in vivo activity against multiple myeloma. Haematologica 2008;93:860-869.

10 Heller G, Schmidt WM, Ziegler B, Holzer S, Müllauer L, Bilban M, Zielinski CC, Drach J, Zöchbauer-Müller S: Genome-wide transcriptional responseto 5-aza-2'-deoxycytidine and trichostatin a in multiple myeloma cells. Cancer Res 2008;68:44-54.

11 Cao Y, Qiu GQ, Wu HQ, Wang ZL, Lin Y, Wu W, Xie XB, Gu WY: Decitabine enhances bortezomib treatment in RPMI 8226 multiple myeloma cells. Mol Med Rep 2016;14:34693475.

12 Niscola P, Siniscalchi A, Tendas A, Scaramucci L, Fratoni S, de Fabritiis P, Caravita T: Chronic myelomonocytic leukemia coexisting with monoclonal gammopathy: concomitant response to azacitidine of both disorders. Ann Hematol 2015;94:1753-1754. 